\title{
Synthesis and Characterization of Black Currant Selenium Nanoparticles
} (Part I)

\author{
Masar J Al-Kurdy ${ }^{1}$ (D), Khalisa K Khudair ${ }^{2}$ (i) and Layla H Al-Kinani ${ }^{3}$ (iD \\ ${ }^{1}$ Department of Nursing Techniques, Technical Institute in Al-Diwaniyah, AL-Furat AL-Awsat Technical \\ University, Iraq, ${ }^{2}$ Department of Physiology, Biochemistry and Pharmacology, College of Veterinary \\ Medicine, University of Baghdad, Iraq, Discipline of Medical, Molecular and Forensic Sciences and \\ School of Veterinary Medicine, Murdoch University, Murdoch, Western Australia
}

\begin{abstract}
The present study aimed to synthesize selenium nanoparticles (SeNPs) using aqueous extract of black currant as a reducing agent. The green synthesized black currant selenium nanoparticles (BCSeNPs) were identified by color change. The characterization of SeNPs was achieved by Ultraviolet-visible (UV-VIS) spectroscopy, scanning electron microscopy (SEM), X-ray diffraction analysis (XRD), and Fourier transform infrared spectroscopy (FTIR). These tests were used to detect: stability, morphology, size, crystalline nature, and functional groups present on the surface of BCSeNPs. The results revealed appearance of the brick-red color indicating the specific color of selenium nanoparticles, and UV-Vis spectroscopy showed band absorbance at $265 \mathrm{~nm}$ of intense surface plasmon resonance manifesting the formation and stability of the prepared BCSeNPs. The SEM image showed the prevalence of spherical selenium nanosized, XRD at $2 \theta$ revealed crystallin selenium nanoparticles, the size was in the average of 18 $50 \mathrm{~nm}$. Furthermore, FTIR revealed the presence of functional groups of the plant which act as stabilizing and reducing agents. In conclusion, the aqueous black currant extract can act as a reducing and capping agent to synthesize BCSeNPs in nano-scale size by a simple method.
\end{abstract}

\section{Keywords: Black currant extract, selenium, nanoparticles, XRD, SEM, FTIR}

\section{Introduction}

Nanotechnology sciences allow to improve the experimental practice of the nanoscale constituent's preparation with exceptional possessions (1). Today, the production of nanoparticles (NPs) using biosynthetic techniques has been considered as a valuable method with increased attraction (2, 3). SeNPs could be chemically (4) or physically (5) synthesized. Moreover, it can even be obtained by the biological way, using microorganisms or extracts of different plants $(6,7)$. Chemically synthesized SeNPs were prepared by reduction of the selenious acid solution using ascorbic acid in the presence of polysaccharides such as acacia gum; glucomannan

*Correspondence: rosmaso@yahoo.com.

Department of Nursing Techniques, Technical Institute in Al-Diwaniyah, AL-Furat AL-Awsat Technical University, Iraq. Received: 7 May 2020, Accepted: 16 August 2020, Published: 28 December 2020.

This articles an open access under the terms and conditions of the Creative Commons Attribution License (CC BY 4.0, https://creativecommons.org/licenses/by/4.0/).

DOI: https://doi.org/10.30539/ijvm.v44i2.974 as well as carboxy methyl cellulose $(8,9)$. Besides, SeNPs could be synthesized via different Gramnegative $(10,11)$, Gram-positive (12) bacteria or fungi $(13,14)$. In the green synthesis of SeNPs, many plant extracts were used as reducing agents including tea extract (15), Allium sativum (16), ferulic acid (17), and Clausena dentata plant leaf extract (18). Besides, spherical SeNPs (size range of 13-18 nm) can be synthesized using dried fruit extract of Vitis vinifera (19). However, many disadvantages due to using chemical or physical methods of SeNPs have been identified, such as extreme temperature, high $\mathrm{pH}$, environmental pollution, as well as they are very expensive methods $(20,21)$. On the contrary, using plant extract (green method) for biosynthesis of nanomaterials has been pointed to possess many advantages compared to biological methods, e.g. it is inexpensive and no special conditions were required $(6,22)$. According to great amount of active ingredients that act as inducing agents in the black currant, such as flavonoids, polyphenol, lignin's, and sugar, this study aimed to synthesize and characterize selenium nanoparticles (SeNPs) 
through a biogenic method using aqueous black currantextract.

\section{Materials and Methods}

Black currant without seed (Vitis vinifera) was purchased from the local market of AL- Diwaniya, Iraq. The rating of black currant was done by the Ministry of Agriculture/ Stat Board for seed testimony in Abu Graib/ Baghdad.

The biogenic synthesis and characterization of SeNPs depended on using black currant aqueous extract without seeds. About $100 \mathrm{gm}$ of black currant without seed was washed with distilled water several times and dried at $40^{\circ} \mathrm{C}$ (incubator) and grinded by blender. A solution of $10 \mathrm{gm}$ of black currant in $100 \mathrm{~mL}$ distilled water was prepared and stirred at $45-50{ }^{\circ} \mathrm{C}$ for $10-20 \mathrm{~min}$ by magnetic hotplate stirrer, and then left at room temperature overnight. The solution was centrifuged at $1000 \mathrm{rpm}$ for $15 \mathrm{~min}$. Whatman ${ }^{\circledR}$ filter paper No.4 was used for separation and filtration of the supernatant. Centrifugation and filtration were repeated twice $(23,24)$. Green synthesis of SeNPs using black currant aqueous extract was prepared as described by $(25-27)$. The $0.1 \mathrm{M}$ of sodium selenite was mixed with black currant extract in a volume ratio of $1: 2$ with adjustment of reaction medium $\mathrm{pH}$ to 8 by using 1 $\mathrm{N}$ of $\mathrm{NaOH}$. The mixture was stirred via magnetic stirrer $(600 \mathrm{rpm})$ at $60-65{ }^{\circ} \mathrm{C}$ for 12 hours in the darkness. The solution was kept overnight, and observed for the formation of red brick color. Color changes occurred due to the reduction of $\mathrm{NaHSeO}_{3}$ to selenium nanoparticles (BCSeNPs). The formation of SeNPs was markedly determined by the appearance of a red brick color. Separation of precipitate from the total solution was done by using high speed cold centrifuge at 15,000 rpm/30 $\min$ at $4{ }^{\circ} \mathrm{C}$. The obtained pellet was then resuspended in deionized water and centrifuged again under the same conditions. This process was repeated three times to remove the organic impurities that exist in BCSeNPs colloid and dried incubator at $45{ }^{\circ} \mathrm{C}$. Characterization of black currant SeNPs (BCSeNPs) was performed by: Ultraviolet-visible spectroscopy (UV-VIS), in which the bio-reduction property of black currants in the synthesis of SeNPs was investigated by UVVIS spectrum (Metertech SP-8001 Taiwan), which is a significant technique to authenticate the formation and stability of BCSeNPs in the colloid as described by $(28,29)$. Furthermore, SEM technique (SEM-Tescan Vega III, Czech) was used to investigate the shape and size of the synthesized BCSeNPs as described by (30), and X-ray diffraction (Shemadzu-6000 Japan) was also used to determine the crystalline amorphous of BCSeNPs as describe by $(31,32)$. Fouriertransform infrared spectroscopy (Shemadzu-8400s, Japan) was used for detecting the functional groups in the biological compound involved in the reactions of nanoparticles synthesis as described by $(33,34)$.

\section{Results and Discussion}

Synthesis and characterization of BCSeNPs revealed brown color after $30 \mathrm{~min}$ and changed gradually to red-brownish color after 72 hours, later, the color became more stable (Figure 1). The biogenic synthesized SeNPs were proven via conversion of the colorless selenious acid to brick red color due to the possibility of conversion of multi-oxidized forms of selenium $\left(\mathrm{Se}^{-2}, \mathrm{Se}^{+2}, \mathrm{Se}^{+4}\right.$ and $\mathrm{Se}^{+6}$ ) to $\mathrm{Se}^{0}$ (35). Encapsulations of $\mathrm{Se} 0$ to organic molecules from the black currant give stabilization to these nanoparticles. The color change upon the addition of selenium selenite to the black currant extract was considered as an indication of SeNPs synthesis (36). This result has been previously obtained by many researchers using different types of green plants (37-40). The characteristic color was attributed to the excitation of the surface plasmon resonance (SPR) (41). The high ability of plants extracts to synthesize SeNPs was attributed to their high content of phenol and flavonoids, in addition to potent reduction capacity (39). The optical absorbance of synthesized BCSeNPs was measured using UV-Vis spectroscopy. An absorption peak between 265$370 \mathrm{~nm}$ confirms the presence of BCSeNPs (Figure 2 ). This absorbance indicated the formation of conjugated compounds, which appeared as indicator to the formed SeNPs. The bio-reduction property of black currants in the synthesis of SeNPs was investigated by UV-VIS spectrum, which is a significant technique to authenticate the stability and formation of BCSeNPs in the solution. The most well-defined peak at $265 \mathrm{~nm}$ represents the SPR of BCSeNPs. The current result is in agreement with the previous studies (42-44) using different types of bacteria and fungi. Concerning SPR, it has been reported that the smallest molecules give the highest peak at UV 
spectroscopy between 280-320 nm (19). The current result was correlated with UV-visible spectra of SeNPs synthesized using orange peel aqueous extract (peak $265.5 \mathrm{~nm}$ ) and the leaf of Petroselinum crispum (peak $270 \mathrm{~nm})(45,46)$.

While Menon and his colleagues (39) synthesized SeNPs using Zingiber officinalea reducing agent, where the peak value was between 370 and $420 \mathrm{~nm}$ that represent SPR. The spherical shape of BCSeNPs was observed according to SEM image with a diameter ranged from 18 to $50 \mathrm{~nm}$ with an average diameter size of $27.10 \pm 1.56 \mathrm{~nm}$ in an electron microscope (Figure 3; Histogram 1). The green synthesized SeNPs using black currant extract showed spherical amorphous NPs with different sizes between 18-50 nm. Spherical SeNPs were synthesized in a range of $30-50 \mathrm{~nm}(47,48)$ and $97 \mathrm{~nm}$ size (49). Spherical shaped SeNPs was also documented by (50) and (39) with size range of 50-100 and 100-150 nm, respectively. Another author reported 30-40 $\mathrm{nm}$ as a range size of SeNPs (51). Black currant polyphenols were found to play a great role in particles size and the final structure of SeNPs dependent on $\mathrm{pH}$, selenium salt molarity, reaction temperature, and reaction time, this result coincides with that of another study (52). In addition, SeNPs aggregation was prevented by organic compounds present in the blank current extract leading to stabilizing SeNPs (53). The usage of raisin or dried V. vinifera in the green synthesis of SeNPs was attributed to its contents of phenols and flavonoids, sugar, iron, calcium and potassium and some vitamins (54). In the current study, a pattern of X-ray diffraction peaks at theta angle-2 value of $14.421,17.941,24.542$ and 29.972, respectively, correspondent to hkl values of $110,101,102$, and 100 crystal planes, were observed (Figure 4). According to the results of $\mathrm{XRD}$ analysis in the current study, the physical characteristic of the particles in the prepared compounds is spherical and crystalized nanoparticles. The size of crystal was in a range of 18 to $50 \mathrm{~nm}$. To clarify the crystalline nature of selenium nanoparticles, XRD analysis was applied, where the result showed different broad diffraction peaks at the lower angle, which goes in line with
(55) and (56) using different plant extracts and with (19) and (57) using raisin.

F-TIR spectroscopy for selenium nanoparticles (Figure 5) showed a distinct peak of BCSeNPs at $3352.39 \mathrm{~cm}^{-1}$ corresponding to $\mathrm{OH}$ : $\mathrm{NH}$ due to Stretch Vibrationin Amide A. While an absorption peak at $2931.90 \mathrm{~cm}^{-1}$ corresponded to $\mathrm{C}-\mathrm{H}$ in $-\mathrm{CH}_{2}$ in aliphatic compounds, the band at $1608.69 \mathrm{~cm}^{-1}$ indicated $\mathrm{NH}_{2}$ in primary amides. The peak at $1514.17 \mathrm{~cm}^{-1}$ is due to $\mathrm{NH}$ in secondary amides (AmideII). The peak at $1359.86 \mathrm{~cm}^{-1}$ attributed to the $\mathrm{C}-\mathrm{H}$ bending in alkanes. However, the peaks at 1066.67 and $1035.81 \mathrm{~cm}^{-1}$ confirmed $\mathrm{C}-\mathrm{O}, \mathrm{C}-\mathrm{C}$ Stretching Vibrations, $\mathrm{C}-\mathrm{O}-\mathrm{H}, \mathrm{C}-\mathrm{O}-\mathrm{C}$ bending vibrations in polysaccharides, protein and polyesters. $\mathrm{C}-\mathrm{X}$ stretching in alkyl halides causes a band at 871.85 and $835.21 \mathrm{~cm}^{-1}$. The bands at 590.24 and $547.80 \mathrm{~cm}^{-1}$ were due to $\mathrm{C}-\mathrm{N}-\mathrm{C}$ bending in amines (58-60). The appearance of many peaks in green synthesized SeNPs indicates different vibrations due to different IR absorption, which is in accordance with $(61,62)$. Also, the characterization of selenium nanoparticles from $\mathrm{V}$. viniferausing FTIR was clarified by (19), who demonstrated the presence of different peaks due to the occurrence of different active components of this plant, which acts as reducing agent. As well as, the presence of lignin in raisin could be claimed by (63), where lignin could be responsible for stabilization of the nanoballs, and this was previouslysuggested by (64). Chen and his colleagues (65) documented that in green synthesis of SeNPs, a high concentration amount of sugars present in dried V. vinifera, such as fructose and glucose, could act as reducing agents. Many amorphous and crystalline forms of selenium can be exist, however the structure, size and shape of SeNPs depend on temperature, concentration, $\mathrm{PH}$, as well as the nature of biomolecules $(42,66)$. In conclusion, it seems that the best conditions for synthesizing selenium nanoparticles using aqueous black currant extract as a reducing agent were under alkaline $\mathrm{pH}(\mathrm{pH} 9)$ and range of temperature between $\left(60-65{ }^{\circ} \mathrm{C}\right)$. This technique can be considered as a good source to synthesize stable SeNPs in lesser time and cost. 

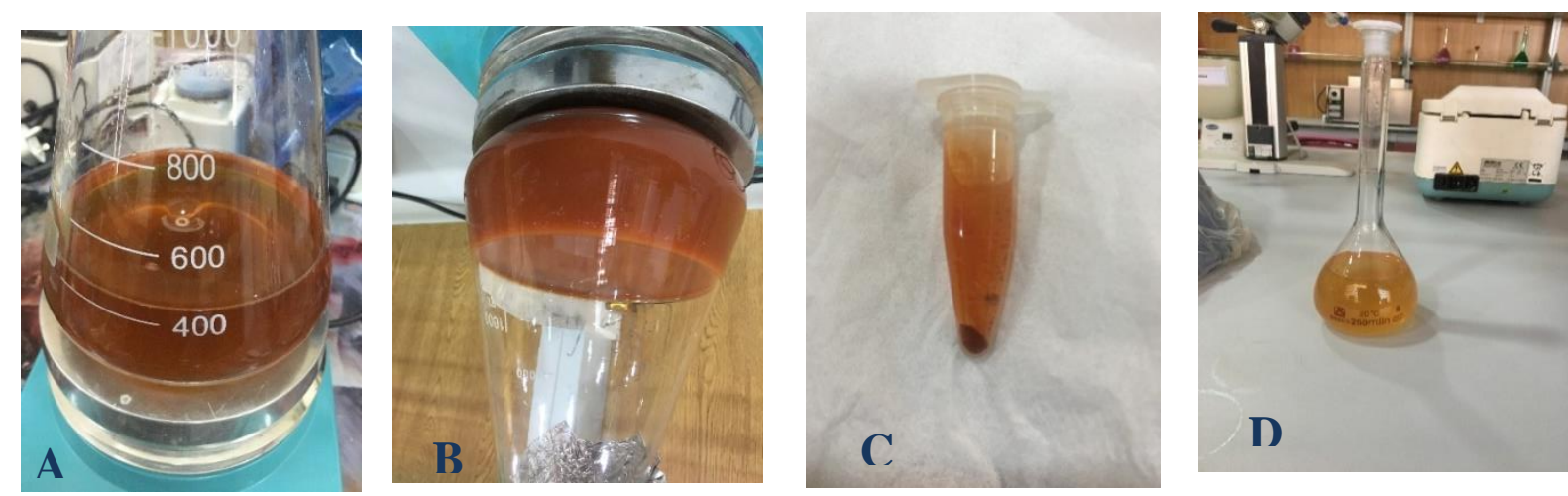

Figure 1. Changing the color after the reduction of sodium selenite to BCSeNPs using black currant extract. A: Image shows black currant aqueous extract, B: Image showed mixture of sodium selenite and black currant extract, C: Image showesBCSeNPs after 48-72 hour, D: Image shows BCSeNPs after centerfication

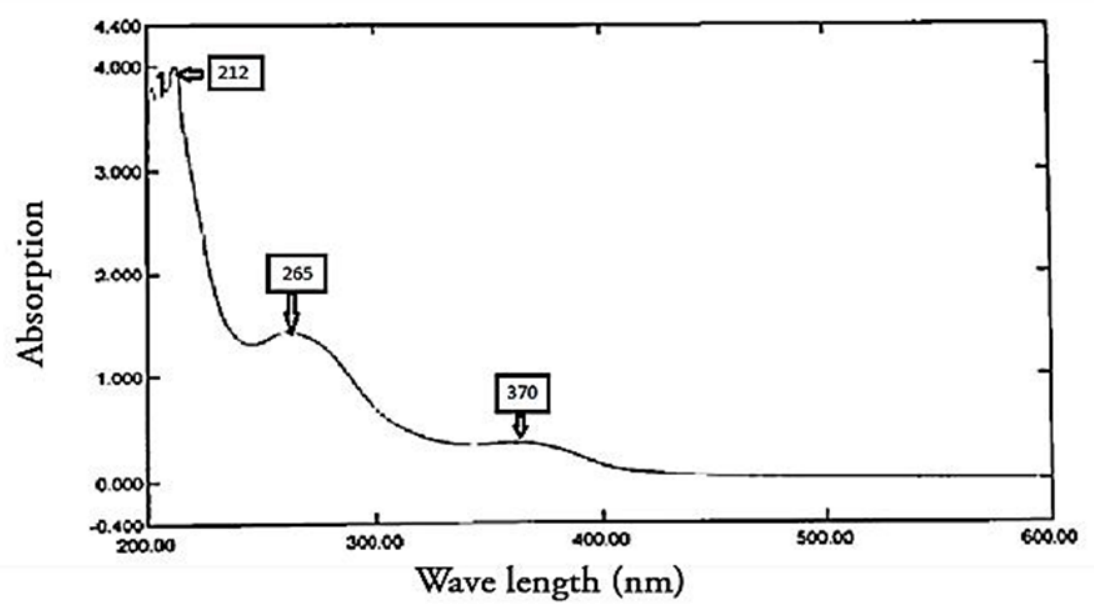

Figure 2. UV-Vis spectroscopy shows absorbance of selenium nanoparticles made from sodium selenite with black currant extract in PH 9

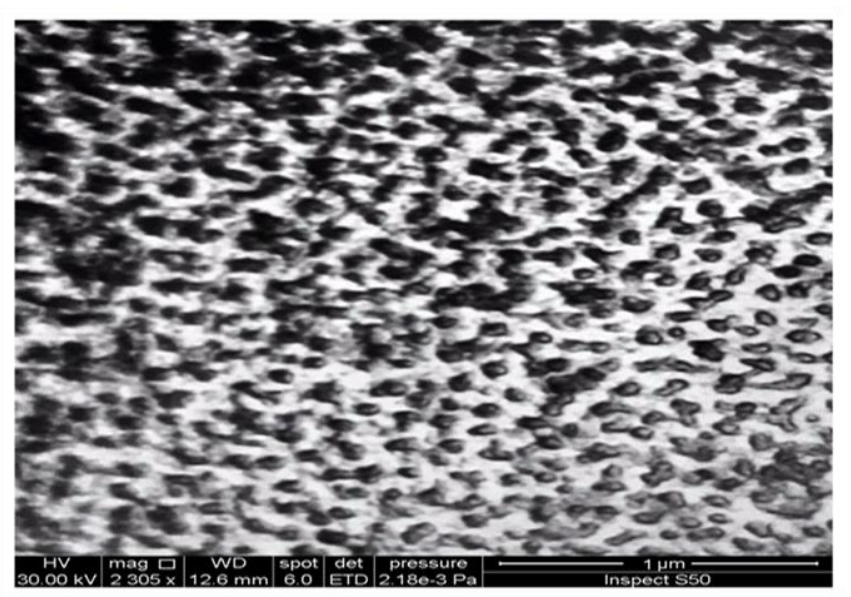

Figure 3. SEM image $(1 \mu \mathrm{m})$ of the selenium nanoparticles made from sodium selenite with black currant extract in percentage 1:2, $v$ : $v$ ratio in $\mathrm{PH} 9$ 


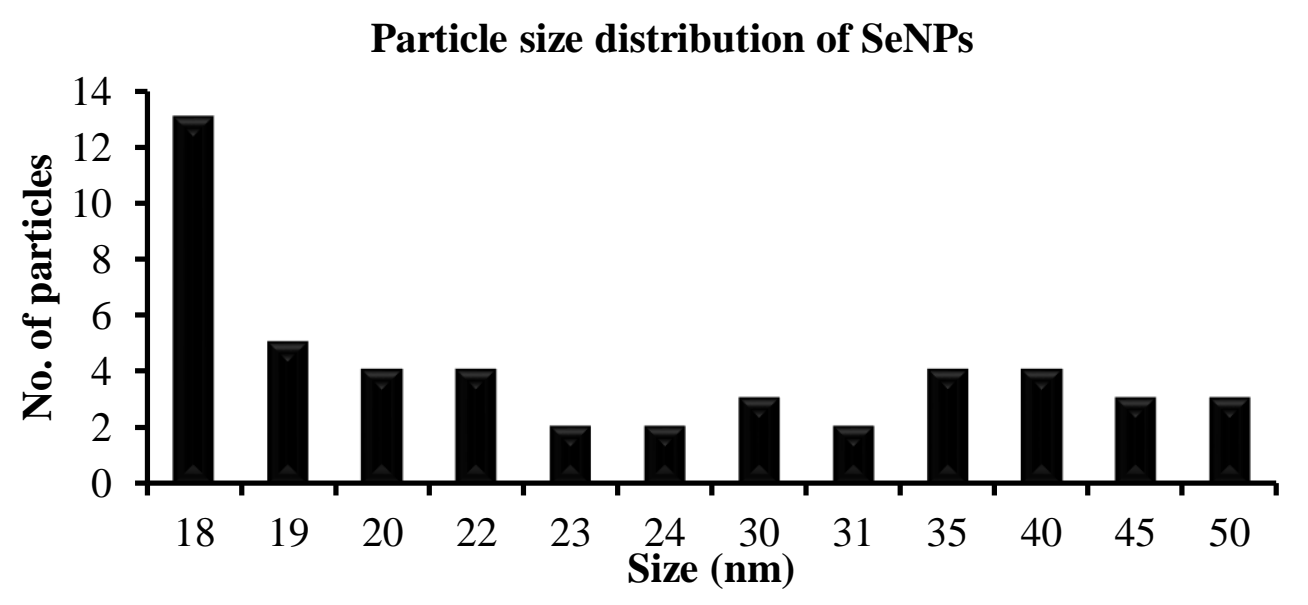

Histogram 1. Diameter distributions of SeNPs

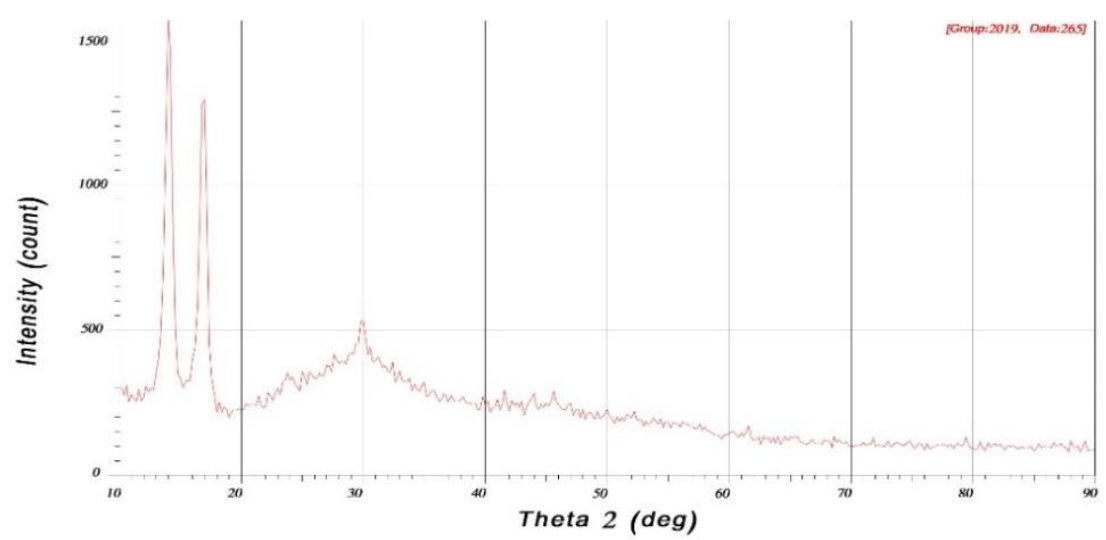

Figure 4. X-ray diffraction pattern for selenium nanoparticles made from sodium selenite with black currant extract in PH 9

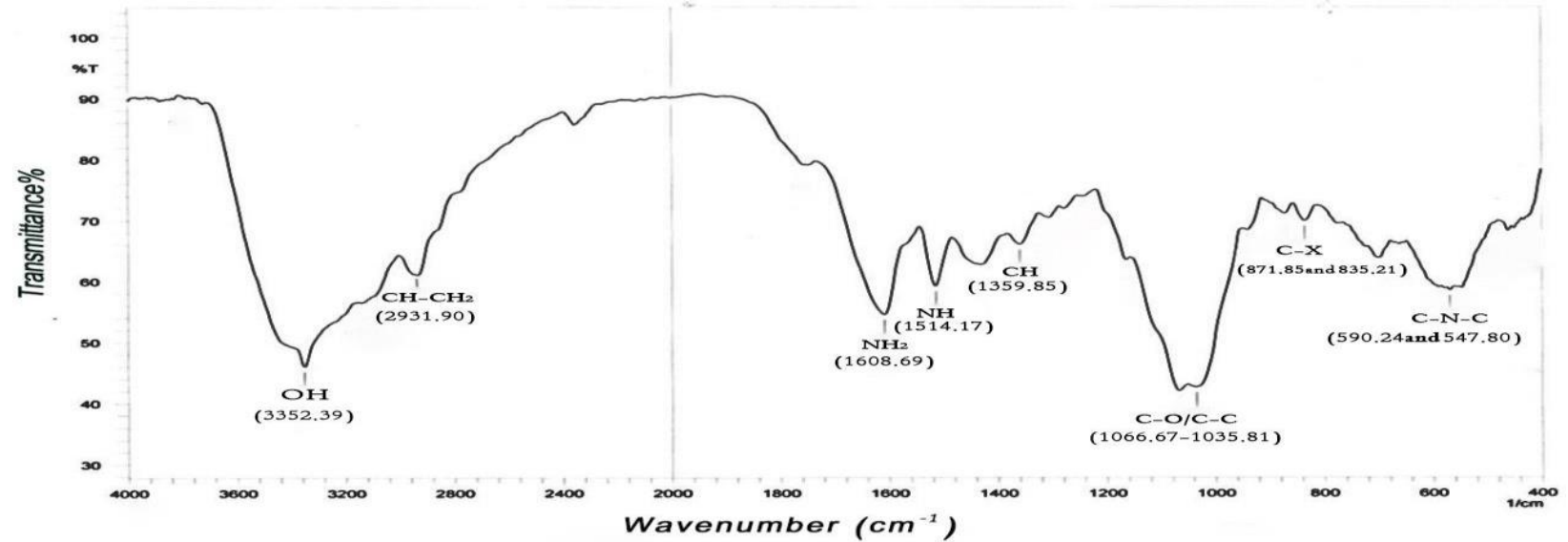

Figure 5. FT-IR spectroscopy for selenium nanoparticles made from sodium selenite with black currant extract in PH 9

\section{Acknowledgements}

Authors would like to express sincere gratitude to the College of Veterinary Medicine /University of Bagdad for supporting this work.

\section{Conflicts of interest}

The authors declare that there is no conflicts of interest. 


\section{References}

1. Prasad M,Lambe UP, Brar B, Shah I,Manimegalai J, Ranjan $\mathrm{K}$, et al. Nanotherapeutics: an insight into healthcare and multi-dimensional applications in medical sector of the modern world. Biomed. Pharmacother. 2018;97: 1521-37.

2. Ebrahimi K, Shiravand S, Mahmoud H. Biosynthesis of copper nanoparticles using aqueous extract of Capparis spinosa fruit and investigation of its antibacterial activity. Marmara Pharm J. 2017;21(4): 866- 71.

3. Khatami M, Amini E,Amini A, Mortazavi SM, Kishani Farahani Z, Heli H. Biosynthesis of silver nanoparticles using pine pollen and evaluation of the antifungal efficiency. Iran J Biotechnol.2017;15: 1-7.

4. Zhang SY, Zhang J, Wang HY, Chen HY. Synthesis of selenium nanoparticles in the presence of polysaccharides. Mater Lett. 2004;58(21):2590-94.

5. Quintana M,Haro-Poniatowski E, Morales J, Batina N. Synthesis of selenium nanoparticles by pulsed laser ablation. Appl Surf Sci.2002; 195(1):175-186.

6. Ramamurthy $\mathrm{CH}$, Sampath KS,Arunkumar P, Kumar MS, Sujatha V,PremkumarK, et al. Green synthesis and characterization of selenium nanoparticles and its augmented cytotoxicity with doxorubicin on cancer cells. Bioprocess Biosyst Eng. 2013;36(8):1131-39.

7. Shoeibi S, Mashreghi M.Biosynthesis of selenium nanoparticles using Enterococcus faecalis and evaluation of their antibacterial activities. J Trace Elem Med Biol.2017; 39:135-39.

8. Agnihotri SA, Mallikarjuna NN, Aminabhavi TM. Recent advances on chitosan-based micro- and nanoparticles in drug delivery. $\mathbf{J}$ Control Release.2004;100(1):5-28.

9. Saini D, Fazil M, Ali MM, Baboota S,Ameeduzzafar A, Ali J. Formulation, development and optimization of raloxifeneloaded chitosan nanoparticles for treatment of osteoporosis. Drug Deliv.2015; 22(6):823836.

10. Dwivedi S,AlKhedhairy AA, Ahamed M,Musarrat J. Biomimetic synthesis of selenium nanospheres by bacterial strain JS11 and its role as a biosensor for nanotoxicity assessment: a novel Se-bioassay. PLoS One. 2013;8(3): 57404.

11. Kazempour ZB,Yazdi MH,Rafii F, Shahverdi AR. Sub-inhibitory concentration of biogenic selenium nanoparticles lacks post antifungal for Aspergillus niger and Candida albicans and stimulates the growth of Aspergillus niger. Iran J Microbiol.2013; 5(1):81-85.

12. Domokos-Szabolcsy E, Marton L, Sztrik A, Babka B, Prokisch J, Fari M. Accumulation of red elemental selenium nanoparticles and their biological effects in Nicotinia tabacum. Plant Growth Regul.2012;68:525-31.

13. Forootanfara H, Zare B,Fasihi-Bam H, Amirpour-Rostami S, Ameri A,Shakibaie M, et al.Biosynthesis and characterization of selenium nanoparticles produced by terrestrial actinomycete Streptomyces microflavus strain FSHJ31. Res Rev J Microbiol Biotechnol.2014; 3(1):47-53.

14. Ahmad M, Yasser M,Sholkamy E, Ali A,Mehanni M. Anticancer activity of biostabilized selenium nanorods synthesized by Streptomyces bikiniensis strain Ess_amA1. Int J Nanomedicine. 2015; 10:3389-3401.

15. ZhangW, Zhang J, Ding D, Zhang L,Muehlmann LA, DengSE, et al. Synthesis and antioxidant properties of Lycium barbarum polysaccharides capped selenium nanoparticles using tea extract. Artif Cells Nanomed Biotechnol.2017;46(7):1463-1470.

16. Ezhuthupurakka IPB, Polaki LR, Suyavaran A,Subastri A, Sujatha V,Thirunavukkarasu C. Selenium nanoparticles synthesized in aqueous extract of Allium sativum perturbs the structural integrity of calf thymus DNA through intercalation and groove binding. Mater Sci Eng C Mater Biol Appl.2017; 74:597-608. 
17. Cui D, Yan C, Miao J, Zhang X, Chen J, Sun $\mathrm{L}$, et al. Synthesis, characterization and antitumor properties of selenium nanoparticles coupling with ferulic acid. Mater Sci Eng C. 2018; 90: 104-112.

18. Sowndarya P, Ramkumar G, Shivakumar M. Green synthesis of selenium nanoparticles conjugated Clausena dentata plant leaf extract and their insecticidal potential against mosquito vectors. Artif Cells Nanomed Biotechnol.2016; 45(8): 1490-1495.

19. Sharma G, Sharma AR, Bhavesh R, Park J, Ganbold B, Nam JS, et al. Biomoleculemediated synthesis of selenium nanoparticles using dried Vitis vinifera (raisin) extract. Molecules.2014;19:2761-70.

20. Iranifam M, FathiniaM, Rad TS, Hanifehpour Y, Khataee AR, JooSW. A novel selenium nanoparticles-enhanced chemiluminescence system for determination of dinitrobutylphenol. Talanta. 2013;107: 263269.

21. Paulraj S, Kumar MS. Biofortification of Food Crops. 8th. New Delhi; Springer. 2016. Chapter 22, Selenium bioavailability through microbes; p.303-316.

22. Ali ZS, Khudiar kk. Synthesis, characterization of silver nanoparticles using Nigella sativa seeds and study their effect on serum lipid profile and DNA damage in blood of hydrogen peroxide treated rats. (Part I).

Iraqi J. Vet. Med. 2019; 43(2): 23-37.

23. Mahmood MS, Gilani AH, Khwaja A, RashidA, AshfaqMK. The in vitro effect of aqueous extract of Nigella sativa seeds on nitric oxide production. Phytother Res.2003;17(8): 921-924.

24. Awan MA, AkhterS, Husna AU, Ansari MS,RakhaBA, AzamA,et al.Antioxidant activity of Nigella sativa seeds aqueous extract and its use for cryopreservation of buffalo spermatozoa. Andrologia. 2018;50(6): e13020.

25. Gottimukkala K, Harika R, Deeveka Z.Green synthesis of iron nanoparticles using green tea leaves extract. J Nanomedine Biotherapeutic Discov. 2017; 7: 1 - 5 .

26. Kaikai B,Bihong H,Jianlin H,Zhuan H, Ran T. Preparation and antioxidant properties of selenium nanoparticles-loaded chitosan microspheres. Int J Nanomedicine. 2017;12: 4527-4539.

27. Wang Z, Cheng F, Mallavarapu M. Characterization of iron polyphenol nanoparticles synthesized by three plant extracts and their fenton oxidation of azo dye. ACS Sustain Chem Eng.2014; 2 (4): 10221025.

28. Mittal AK,Chaisti Y, Banerjee UC.Synthesis of metallic nanoparticles using plant extracts. Biotechnol. Adv.2013. 31:346-356.

29. Banerjee P, Satapathy M,Mukhopahayay A. Das P. leaf extract mediated green synthesis of silver nanoparticles from widely available indian plants: synthesis, characterization, antimicrobial property and toxicity analysis. Bioresour Bioprocess. 2014;1: 3.

30. Mittal AK, Tripathy D, Choudhary A, Aili PK, ChatterjeeA, Singh IP. Biosynthesis of silver nanoparticles using Potentilla fulgens Wall. ex Hook. and its therapeutic evaluation as anticancer and antimicrobial agent. Mater Sci Eng C.2015; 53:120-127 .

31. Rolim WR, Pelegrino MT, de Araújo Lima B, Ferraz LS, Costa FN,Bernardes JS.Green tea extract mediated biogenic synthesis of silver nanoparticles: Characterization, cytotoxicity evaluation and antibacterial activity. Appl Surf Sci.2019; 463:66-74 .

32. Rietveld HA. Profile refinement method for nuclear and magnetic structures. JAppl Crystallogr.1969; 2:65-71.

33. Holzwarth U, Gibson N. The scherrer equation versus the Debye-Scherrer equation. Nat Nanotechnol.2011; 6:534.

34. Khoshnamv M, Huo C, Liu J. Silver nanoparticles synthesis using Allium ampeloprasum L. leaf extract: characterization and performance in catalytic reduction 
of 4-nitrophenol and antioxidant activity. J. Mol. Struct.2018; 1175:90-96.

35. Torres SK, Campos VL, León CG, Rodríguez-Llamazares SM, Rojas SM, González $\mathrm{M}$,et al. Biosynthesis of selenium nanoparticles by Pantoe aagglomerans and their antioxidant activity. J Nanopart Res. 2012;14 (11): 1236.

36. BajajM, Schmidt S, WinterJ. Formation of Se (0) nanoparticles by Duganellasp. and Agrobacterium sp. isolated from Se-laden soil of North-East Punjab, India.Microb. Cell Fact. 2012;11(1):64.

37. Cui D, LiangT, Sun L, Meng L, Yang C, Wang L, et al. Green synthesis of selenium nanoparticles with extract of hawthorn fruit induced HepG2 cells apoptosis. Pharmaceutical Biology.2018; 56(1): 528-534.

38. AL-Taie AT. Physiological Role of Propolis Biogenic Selenium Nanoparticles on Intestinal Homeostasis of Heat Stressed Rats [Dissertation]. Baghdad, Iraq: university of Baghdad; 2019.

39. Menon S, KS SD, Agarwal H, Shanmugam VK. Efficacy of biogenic selenium nanoparticles from an extract of ginger towards evaluation on anti-microbial and antioxidant activities. Colloid Interface Sci Commun.2018; 29:1-8.

40. Sofer Z, Bartůněk V, Junková J, Ulbrich P, Babuněk M, Kuchař M. Synthesis of spherical amorphous selenium nano and microparticles with tunable sizes, Micro Nano Lett. 2016;11:91-93

41. Wang T, Yang L, Zhang B, Liu J. Extracellular biosynthesis and trans-formation of selenium nanoparticles and application in $\mathrm{H}_{2} \mathrm{O}_{2}$ biosensor. Colloids Surf B Biointerfaces. 2010;80(1): 94-102.

42. Fesharaki $P$, Nazari $P$, Shakibaie $M$, Rezaie $S$, Banoee M, Abdollahi M. Biosynthesis of selenium nanoparticles using Klebsiella pneumoniae and their recovery by a simple sterilization process. Braz. J. Microbiol. 2010; 41: 461-466.
43. Zhang W, Chen Z, Liu H, Zhang L, Gao P, Li D. Biosynthesis and structural characteristics of selenium nanoparticles by Pseudomonas alcaliphila. Colloids Surf B.2011; 88:196202.

44. Harikrishnan H, Abdullah N, Ponmurugan K, Shyam R. Microbial synthesis of selenium nanocomposite using Saccharomyces cerevisiae and its antimicrobial activity against pathogens causing nosocomial infection. Chalcogenide Lett.2012; 9: 509515.

45. Sasidharan S, Sowmiya R, Balakrishnaraja R.Biosynthesis of selenium nanoparticles using citrus reticulata peel extract. World J. Pharm. Res.2014; 4: 1322-1330.

46. Fritea L, Laslo V,Cavalu S, Costea T,Vicas SI.Green biosynthesis of selenium nanoparticles using parsley (petroselinumcrispum) leaves extract. Studia Univ. VG, SSV.2017; 27(3): 203-208.

47. Bunglavan SJ, Garg AK, Dass RS, Shrivastava S. Effect of supplementation of different levels of selenium as nanoparticles/sodium selenite on blood biochemical profile and humoral immunity in male Wistar rats. Vet World. 2014; 7(12):1075-1081.

48. Riva B, Bellini M, Corvi E, Verderio P, Rozek E,Colzani B, et al. Impact of the strategy adopted for drug loading in nonporous silica nanoparticles on the drug release and cytotoxic activity. J Colloid Interface Sci.2018; 519:18-26.

49. Gautam PK, Kumar S,Tomar MS, Singh RK, Acharya A, Ram B. Selenium nanoparticles induce suppressed function of tumor associated macrophages and inhibit Dalton's lymphoma proliferation. BiochemBiophys Rep.2017; 12:172-184.

50. Bai K, Hong B, Huang W, He J. Seleniumnanoparticles-loaded chitosan/chito oligosaccharide microparticles and their antioxidant potential:a chemical and in vivo investigation. Pharmaceutics.2020; 12(1), 43. 
51. Bhattacharjee A,Basu A, Ghosh $P$, Biswas J, Bhattacharya S. Protective effect of selenium nanoparticle against cyclophosphamide induced hepatotoxicity and genotoxicity in swiss albino mice. J Biomater Appl. 2014; 29(2): 303-317.

52. Razi MK, Maamoury RS, Banihashemi S. Preparation of nanoselenium particles by water solution phase method from industrial dust. dust. Int. J. Nano. Dim.2011; 1(4):2617.

53. Suresh D, Nethravathi PC, Udayabhanu $H$, Rajanaika H, Nagabhushana H, Sharma SC. Green synthesis of multifunctional zinc oxide nanoparticles using Cassia fistula plant extract and their photodegradative, antioxidant and antibacterial activities. Mater Sci Semicond Process. 2015; 31: 446-454.

54. Wu CD.Grape products and oral health. J Nutr.2009; 139(9): 1818S-1823S.

55. Ingole A, Thakare $\mathrm{S}$, Khati $\mathrm{N}$, Wankhade A, Burghate D. Green synthesis of selenium nanoparticles under ambient condition. chalcogenide Lett. 2010; 7:485-489.

56. Saratale RG, Benelli G, Kumar G, Kim DS, Saratale GD. Bio-fabrication of silver nanoparticles using the leaf extract of an ancient herbal medicine, dandelion (Taraxacumofficinale), evaluation of their antioxidant, anticancer potential, and antimicrobial activity against phytopathogens. Environ Sci Pollut Res.2017; 25(11):1039210406.

57. Sarkar B, Bhattacharjee S, Daware A, Tribedi P, Krishnani KK, Minhas PS. Selenium nanoparticles for stress-resilient fish and livestock. Nanoscale Res Lett.2015; 10(1): 371.

58. Kamnev AA, Mamchenkova PV, Dyatlova YA, Tugarova AV. FTIR spectroscopic studies of selenite reduction by cells of the rhizobacterium Azospirillum brasilense Sp7 and the formation of selenium nanoparticles. $\mathrm{J}$ Mol Struct.2017;1140: 106-112.
59. Tugarova AV,Mamchenkova PV,Dyatlova YA,Kamnev AA. FTIR and Raman spectroscopic studies of selenium nanoparticles synthesised by the bacterium Azospirillum thiophilum. Spectrochim Acta A Mol BiomolSpectrosc. 2018; 192: 458-463.

60. Alagesan V, Venugopal S. Green synthesis of selenium nanoparticle using leaves extract of withania somnifera and its biological applications and photocatalytic activities. Bionanoscience. 2019; 9(1): 105-116.

61. Xu C, Zhang S, Chuang C, Miller E, Schwehr K, Santschi P. Chemical composition and relative hydrophobicity of microbial exopolymeric substances (EPS) isolated by anion exchange chromatography and their actinide binding affinities. Marine Chemistry. 2011;126: 27-36.

62. Wang L, Wang L, Ren X, Ye X, Li W, Yuan $\mathrm{S}$, et al. $\mathrm{pH}$ dependence of structure and surface properties of microbial EPS. Environ. Sci. Technol.2012; 46: 737-744.

63. Arias MC. Binderless fiberboard production from Cynara cardunculus and Vitis vinifera [Dissertation]. Tarragona and Reus,Spain: UniversitatRovirai Virgili; 2008.

64. Coccia F,Tonucci L, Bosco D,Bressand M, D'Alessandro N. One pot synthesis of ligninstabilized platinum and palladium nanoparticles and their catalytic behavior on oxidation and reduction reactions. Green Chem.2012; 14:1073-1078.

65. Chen A, Shin D, Nam J, Kwon K, Yoo J. Selenium nanowires and nanutubes synthesized via a facile template-free solution method. Mater Res Bull. 2010;45: 699-704.

66. Yu Y, Bai F, Wang W, Liu Y, Yuan Q, Qu $\mathrm{S}$,et al. Fibroblast growth factor 21 protects mouse brain against d-galactose-induced aging via suppression of oxidative stress response and advanced glycation end products formation. Pharmacol Biochem Behav.2015; 133, 122-131. 


\section{تصنيع وتثخيص جسيمات السيلينيوم النانوية باستخدام الزبيب الاسود

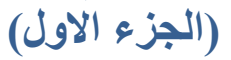

مسار جبار جري الكردي1، خالصة كاظم خضير ²، ليلى الكناني3

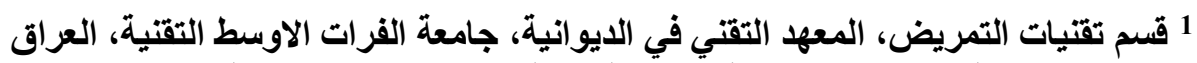

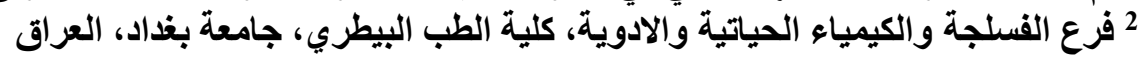

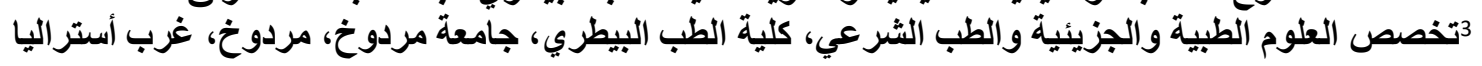

\section{الخلاصة}

هدفت الدراسة الحالية الى تصنيع جسيمات السيلينيوم النانوية باستخدام المستخلص المائي للزبيب الأسود كعامل اختزال. التصنيف التئيع الحيوي

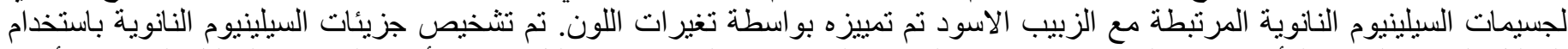

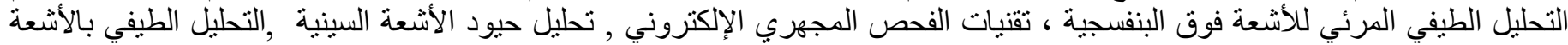

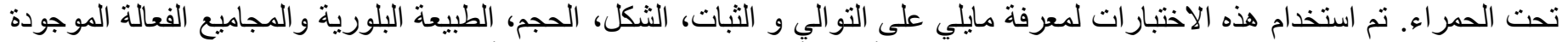

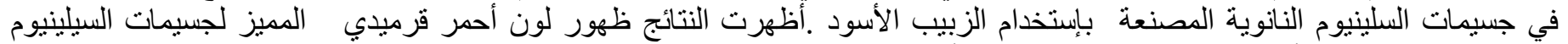

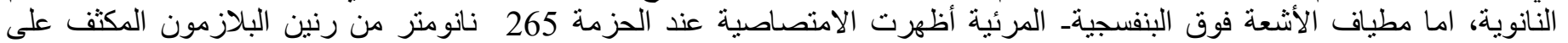

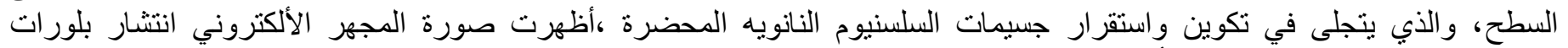

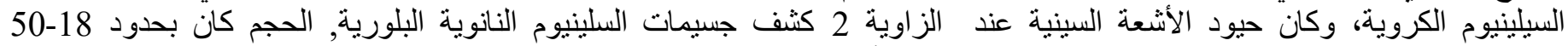

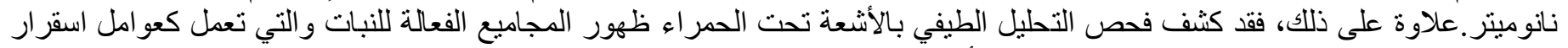

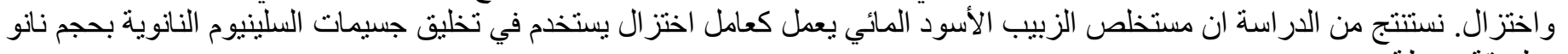
وطريقة بسيطة. الكلمات المفتاحية: مستخلص الزبيب الأسود، السيلينيوم، الجسيمات النانوية، التصنيع الحيوي. 